\title{
EDITORIAL
}

\section{LESSONS FROM ZIKA VIRUS (ZIKV) EPIDEMICS AND UPCOMING OLYMPIC 2016}

Received: 25 March 2016

Zika virus (ZIKV) is a member of the virus family Flaviviridae and the genus Flavivirus. It is spread by daytime-active Aedes mosquitoes. Its name comes from the Zika Forest of Uganda. Zika may spread from a pregnant woman to the baby. This may result in microcephaly and other severe brain problems.

Zika Virus was discovered in 1947 in Uganda $^{1}$, and had until recently remained as an obscure virus confined to a narrow equatorial belt running across Africa and into Asia. The first isolation of the virus was made in April 1947 from the serum of a pyrexial rhesus monkey caged in

the canopy of Zika Forest (zika meaning "overgrown" in the Uganda language), near the East African Virus Research Institute in Entebbe, Uganda. The virus spread eastward across the Pacific Ocean 2013-2014 Zika virus outbreaks in Oceania to French Polynesia, New Caledonia, the Cook Islands, and Easter Island, and in 2015 to Mexico, Central America, the Caribbean, and South America, where the Zika outbreak has reached pandemic levels.. These reports indicate a possible association between Zika Virus infection and congenital malformations and severe neurological and autoimmune complications. In particular, an increase in the incidence of $\mathrm{Zika}$ infection towards the end of 2013 was followed by a rise in the incidence of Guillain-Barré syndrome ${ }^{1}$.

In South America, the first reports of locally transmitted infection came from Brazil. On July 2015, exactlyone year after hosting the soccer World Cup, Brazil reported an association between Zika Virus infection and Guillain-Barré syndrome. Three months later, on October 2015 Brazil reported an association between Zika Virus infection and microcephaly . Epidemiological data indicate that up to Feb 2, 2016, 5079 suspected cases of microcephaly were reported in 21 Brazilian States. This incidence of microcephaly is 20 times higher than in previous years, reaching 99.7 per 100,000 livebirths, and including 76 deaths of neonates as of Jan 6, 2016². March'2016 Bangladesh confirmed its first case of the Zika virus in an old sample of blood from a 67-year old man who had not been overseas.
Accepted: 24 May 2016 \& published 27 May 2016
On February 1, 2016 WHO declared the Zika Virus spread in South American and Caribbean countries a "Public Health Emergency of International Concern", or simply a "PHEIC" 2 , Zika is the fourth epidemic that deserves such an international alarm: Ebola, Polio and H1N1 Influenza infection are the other 3 conditions that caused such a statement ${ }^{4}$. More than 50 countries have reported cases of Zika Virus infection until March 2016, and these numbers shall increase. The biggest hazard and concern posed by this world epidemic is the risk of microcephaly among newborns.

The idea of hosting world events such as the FIFA Soccer World Cup in 2014 and the Olympic Games in 2016 in Brazil is now on serious debate due to intense gathering of euphoric crowd to the reality that neither Brazil's real problems of poverty and social inequality nor the economic or the environmental challenges will even minimally be faced. Hosting mass events for the country can start create catastrophe within and outside of Brazil is big concern of health authority including WHO. Inadequate Sanitation ${ }^{5}$, is a current challenge in Brazil which are strongly associated with the difficulty to control epidemics. Vector control is crucial for containment for Zika infection. But no such government campaigns as "Zika Zero" (an unreal, illusionary goal) and "60 million people are stronger than a mosquito" 6 (current government campaigns) show minimal effects on solving the problem, since the epidemic numbers keep increasing. The Brazilian government focuses on convincing their population that the Aedes aegypti is the single source of the problem, whilst its real reason are, in fact, centuries of neglected investments on basic sanitation of Brazil. Three months before the Rio 2016 Olympic Games a World Health Organization Statement recommended athletes and visitors of Rio de Janeiro to "avoid visiting impoverished and over-crowded area with no piped water and poor sanitation" 7. This statement understands that "the risk of being bitten [by the Aedes mosquito] is higher". 
A key prospective study was published on March 2016, describing the clinical features of 88 pregnant women in Rio de Janeiro, Brazil, who had a rash within 5 days. Among them, $82 \%$ tested positive for Zika, 28\% had fever, fetal abnormalities were detected by ultrasonography in $29 \%$ of positive testers. The study confirms previous reports of the association between Zika virus infection and an elevated risk of fetal death, placental insufficiency and CNS injury ${ }^{8}$. On February 2016 the CDC published a Clinical Protocol indicating how to deal with the possibility of a Zika virus infection. Microcephaly is a clinical finding and not a disease. Since the growth of the cranium depends on the forces of an expanding brain, microcephaly is an indicator of an undersized brain but the clinical implications of an undersized

brain are far more complex to establish ${ }^{9}$. In Paraiba state, Northeastern Brazil, six children diagnosed with Zika virus were born to mothers who were apparently symptomatic during pregnancy, all of them with neonatal Head Circumference below the 10th percentile. Fetal neurosonograms showed two cases with cerebellar involvement and three with brain calcifications. One had severe arthrogryposis ${ }^{5}$. This cases shows severe fetal brain injury associated with Zika virus infection with vertical transmission. Recently, the virus was found in amniotic fluid of two fetuses that were found to have microcephaly, which was consistent with intrauterine transmission of the virus ${ }^{10}$. Described cases were characterized by severely affected CNS (neurotropism of the virus) and gross intrauterine growth retardation. Calcifications in the placenta and a low placentalfetal weight ratio, indicate potential damage to the placenta by the virus.

Important bioethical questions are being raised by the Zika Virus epidemic. The 2011 WHO Health Convention states that "maternity is a social function", and therefore women should have the right to freely and responsibly decide on their pregnancies. These rights are especially important when a mother is infected by Zika and needs specific care, before or during pregnancy,

and after carriage ${ }^{11}$. The currently affected countries by the Zika epidemic, most of them located in Latin America, also share a common restriction: their laws forbid or restrict the possibility of abortion, frequently based on the bioethical principle of the "sanctity of life".

Prospects for research are to better assess the efficacy and the risks of proposed ways of vector control, such as social participation, genetically modified mosquitoes, Wolbachia infection in mosquitoes, irradiation, and the environmental risks associated with a possible indiscriminate use of environmental agents to kill the mosquitoes; Possible effective drugs to treat Zika infection in pregnant women and prevent CNS lesions of the newborn, especially during the first 3 months of pregnancy; to discuss bioethical issues raised by the severe damages to newborns, such as the right of pregnant women to decide about their pregnancy outcomes.

The legacy of the Rio 2016 Olympic Games is increasingly being associated with current ineffective public policies on dealing with epidemics. Efforts should be made to understand and better organize the health systems of the Latin American countries affected by this epidemic, since they are so far not prepared to handle with Zika and its life-long clinical consequences. Public Health policies in these countries have now to reset priorities towards controlling it as quick as possible.

\section{Quazi Tarikul Islam', Md Robed Amin ${ }^{2}$}

${ }^{1}$ Prof of Medicine, Popular Medical College, Editor in Chief, ${ }^{2}$ Assoc Prof of Medicine, Dhaka Medical College, Executive Editor

\section{References:}

1. Disk, G.W.A., Kitchen, S.F. and Haddow, A.J. (1952) Communications 509-Zika Virus (I). Isolations and Serological Specifity. Transactions of the Royal Society of Tropical Medicine and Hygiene, 46, 34.

2. Roby, J.A., Pijlman, G.P., Wilusz, J. and Khromykh, A.A. (2014) Noncoding Subgenomic Flavivirus RNA: Multiple

Functions in West Nile Virus Pathogenesis and Modulation of Host Responses. Viruses, 6, 404-427.

3. World Health Organization (2016) WHO Statement on the First Meeting of the International Health Regulations (2005)(IHR 2005) Emergency Committee on Zika Virus and Observed Increase in Neurological Disorders and Neonatal Malformations. Saudi Medical Journal, 37, 332-333.

4. Villarreal, P.A. (2016) Zika Virus as a Public Health Emergency of International Concern: Insights from PreviousCases. Groningen Global Health Law.https: / ghlgblog.wordpress.com/2016/02/ 08/zika-virus-as-a-public-health-emergency-ofinternational-concern-insightsfrom- previous-cases / \#more-592 
5. World Health Organization (WHO). Health Topics: Sanitation. http://www.who.int/topics/ sanitation/en/

6. Brazilian Ministry of Education: National Campaign for the Prevention against Aedes aegypti.http:// zikazero.mec.gov.br/

7. World Health Organization (WHO). Zika Virus and the Olympic and Paralympic Games Rio 2016. WHO Statement, 12 May 2016, Media Centre. http:// www.who.int/mediacentre/news / statements / 2016/zika-olympics/en/

8. Brasil, P., Pereira Jr., J.P., Raja Gabaglia, C., Damasceno, L., Wakimoto, M., Ribeiro Nogueira, R.M., Carvalho deSequeira, P., Machado Siqueira, A., Abreu de Carvalho, L.M., Cotrim da Cunha, D., Calvet, G.A., et al. (2016) ZikaVirus Infection in Pregnant Women in Rio de Janeiro-Preliminary Report. The New England Journal of Medicine.http:// dx.doi.org/ 10.1056/NEJMoa1602412
9. Soares de Araújo, J.S., Regis, C.T., Gomes, R.G.S., Tavares, T.R., Rocha dos Santos, C., Assunção, P.M., et al. (2016)Microcephaly in Northeast Brazil: A Review of 16208 Births between 2012 and 2015. Bulletin of the World Health Organization

10. Mlakar, J., Korva, M., Tul, N., Popovi, M., PoljšakPrijatelj, M., Mraz, J., Kolenc, M., Rus, K.R., Vipotnik, T.V., Vodušek, V.F., Vizjak, A., Pi•em, J., Petrovec, M. and •upanc, T.A. (2016) Zika Virus Associated with Microcephaly. The New England Journal of Medicine, 374, 951-958. http://dx.doi.org/ 10.1056/NEJMoa1600651

11. United Nations General Assembly: Sixty-Sixth Session. Right of Everyone to the Enjoyment of the Highest AttainableStandard of Physical and Mental Health.https: / / documents-dds-ny.un.org/doc/ UNDOC/GEN / N 11 / 443/58/PDF/N1 144358.pdf? OpenElement 